\title{
Host response, malnutrition and oral diseases. Part 1
}

\author{
SYLWIA MAEGORZATA SŁOTWIŃSKA ${ }^{l}$, ROBERT SŁOTWIŃSKR ${ }^{2,3}$
}

${ }^{1}$ Department of Conservative Dentistry, Medical University of Warsaw, Poland

${ }^{2}$ Department of Immunology, Biochemistry and Nutrition, Medical University of Warsaw, Poland

${ }^{3}$ Department of Surgical Research and Transplantology, Mossakowski Medical Research Center, Polish Academy of Sciences, Warsaw

\begin{abstract}
Effective defense response of the body requires the proper nutritional and metabolic preparation and adequate energy expenditure. Every pathological process with coexisting malnutrition is subject to an increased risk of failure and complications in medical treatment, which is a serious threat to human health and life. Malnutrition, particularly protein-calorie malnutrition, is characterized by a decrease in resistance, particularly involving cellular immune deficiency, which in turn causes a significant decrease in resistance to infections. Inflammation is the price that the organism has to pay for the effective antimicrobial defense. Therefore, uncontrolled changes may occur in the immune system in nutrition disorders, especially in a significant protein-calorie malnutrition, which in turn prevents the correct response to microbial infection, including bacterial infection, which occurs in the course of periodontitis or untreated caries disease. Research determining the relationship between the clinical state of oral health, selected immune parameters and indicators of nutritional status of the organism, is an alternative to other attempts undertaken to reduce these risks.
\end{abstract}

Key words: malnutrition, host response, oral diseases.

(Centr Eur J Immunol 2014; 39 (4): 518-521)

Nutritional status of the organism has an important impact on the proper functioning of the human immune system and antimicrobial resistance as well as effective inflammatory response in the course of various diseases. Effective defense response of the body requires the proper nutritional and metabolic preparation and adequate energy expenditure. Therefore, any pathological processes with coexisting malnutrition are subject to an increased risk of failure and complications in medical treatment, which is a serious threat to human health and life $[1,2]$.

Malnutrition, particularly protein-calorie malnutrition, is characterized by a decrease in resistance, particularly involving cellular immune deficiency, which in turn causes a significant decrease in resistance to infections. Chronic starvation leads to progressive atrophy of the thymus and a significant decrease in the total pool of lymphocytes. The function of T lymphocytes and the complement system is impaired after the complete atrophy of the thymus. Chronic malnutrition causes a decrease in the level of proteins, in particular albumin, leading to disturbances in the metabolism of cytokines, especially pro-inflammatory cytokines: tumor necrosis factor $\alpha$ (TNF- $\alpha$ ), interleukin (IL)- $1 \beta$ and IL-6. The inhibition of the production of IL-1 is particularly dangerous as it contributes to a drastic reduction in lymphocyte proliferation $[3,4]$. The weakening of the function of the complement pathway, in turn, causes impairment of phagocytic and chemotactic activity of the immune system, resulting in weakening of the antimicrobial activity of the organism. A significant correlation has been found between the parameters of cellular immunity and the degree of malnutrition of the body. It was calculated that the total count of lymphocytes amounting to $900-1500 / \mathrm{mm}^{3}$ indicates the average degree of malnutrition of the organism, whereas the severe malnutrition is characterized by lymphocyte count $<$ $900 / \mathrm{mm}^{3}$. The percentage of peripheral blood lymphocytes is also reduced [5, 6]. The functioning of leukocytes is subject to a significant impairment, the production of antibodies is reduced as well as the concentration of complement components. Therefore, uncontrolled changes may occur in the immune system in nutrition disorders, especially in a significant protein-calorie malnutrition, which in turn prevents the correct response to microbial infections, including bacterial infections, which occur in the course of periodontitis or untreated caries disease $[7,8]$.

Periodontitis is a chronic inflammation of the tissues that surround and support the teeth in alveoli, caused by specific microorganisms derived from dental plaque. It is characterized by infiltration of leukocytes, mainly neutrophils, local loss of connective tissue, alveolar bone resorption and the occurrence of periodontal pockets. Bacteria of 
several species are listed among the potential pathogens: Porphyromonas gingivalis, Tannerella forsythia, Prevotella intermedia, Fusobacterium nucleatum, Campylobacter rectus, Eikenella corrodens, Aggregatibacter (Actinobacillus) actinomycetemcomitans and Spirochaetes [9, 10]. Physico-chemical properties of saliva, quality and type of diet as well as the way of eating play a very important role in the formation and maturation of a bacterial biofilm plaque $[11,12]$. Periopathogenic antigens penetrating into the body may modulate the host response in a very different manner. Bacteria of the two most periopathogenic species, i.e. Porphyromonas gingivalis and Aggregatibacter actinomycetemcomitans, have been particularly thoroughly investigated $[13,14]$. The experimental studies in rats have demonstrated that gingival epithelial cells, colonized by strains of Aggregatibacter actinomycetemcomitans, following the stimulation with interferon $\gamma$ (IFN- $\gamma$ ), expressed major histocompatibility gene complex MHC class II and molecules present on the surface of B cells - B7-1/ CD80. These molecules presented an antigen to $\mathrm{T}$ cells by binding to a specific CD4+ receptor present on their surface, thus initiating the humoral immune response. Importantly, the CD4+ receptors of T cells were not activated when the strain Aggregatibacter actinomycetemcomitans was not present in the gingival epithelial cells. The ability to colonize the gingival epithelium by selected strains of the species Aggregatibacter actinomycetemcomitans is determined by a precisely-defined sequence of 14 genes on the chromosome, designated as tad (tight adherence). Administration, to the experimental rats, of the suspension of antigens derived from Aggregatibacter actinomycetemcomitans strain with a defect in the tad sequence did not provoke an immune response, and consequently, there was no expected damage observed of connective tissue and the destruction of lamina dura of the alveolar bone [15]. Studies on the virulence of bacteria of the Porphyromonas gingivalis species showed that the proteolytic enzymes derived from membrane vesicles of these microorganisms are capable of inhibiting the HLA-DR- $\alpha$ gene expression, induced by IFN- $\gamma$, and may affect gene transcription of a protein inducing the action of IFN- $\gamma$, CII TA class II transactivator [16].

The results of the above selected experimental studies suggest that some of the most periopathogenic microorganisms, bacteria of the Porphyromonas gingivalis and Aggregatibacter actinomycetemcomitans species, have the ability to modulate or block the body's immune response by disrupting proper functioning of cells. Malnutrition also changes and/or weakens the human immune system, thereby increasing the susceptibility of periodontal tissue to inflammatory agents and foreign antigens, which in unfavorable conditions leads to a synergistic adverse effect of bacterial plaque and dietary deficiency.

Assessment of the effects of malnutrition on the cellular level indicates that the imbalance in nutrients, including major nutrient and trace element antioxidants, may influence the biological gradients and homeostasis of the human body, including the local integrity of the periodontal tissues.

A healthy and properly nourished body uses all the available host defense functions in order to maintain a kind of mutual non-aggression pact with potential periodontal pathogens [17].

The pathogenesis of periodontal disease can be divided into four stages: the colonization of microorganisms, invasion, damage and healing. Studying the importance of malnutrition in the pathogenesis of periodontal disease should be considered separately for all four time periods. Deficiencies in the supply of nutrients can affect both the oral microbial ecosystem as well as all the mechanisms involved in specific phases of growth and progress of lesions within periodontium and repair processes.

The type of diet and way of eating, as well as saliva, play a significant role in the formation and maturation of plaque. Saliva is a complex secretion of the salivary glands, which contains proteins, glycoproteins, electrolytes, small organic molecules and substances originating from the blood and alveolar fluid. Malnutrition reduces the amount of saliva produced, and its antibacterial and physicochemical properties are significantly deteriorated. In malnourished persons, a reduced content of certain proteins in the saliva is observed, including the secretory immunoglobulin $\mathrm{A}$ ( $\mathrm{sIg} \mathrm{A})$, which is a result of severe atrophy of salivary gland secretory cells [18]. In experimental animals with experimentally-induced protein-calorie deficiency, a significant deterioration was observed in protein synthesis of parotid and submandibular gland [19]. Furthermore, in malnutrition there is a significant reduction in the activity of glycoproteins agglutinating microorganisms present in saliva, which is one of the causes of increased accumulation of bacterial dental plaque [20].

One of the most common forms of periodontal disease in impoverished communities of the Third World is necrotizing ulcerative gingivitis. It is believed that the primary cause of this situation is widespread very poor state of oral hygiene in these environments [21, 22]. Studies conducted in Africa, India and South America have shown that necrotizing ulcerative gingivitis occurs mainly in young children who live in extreme poverty and very poor sanitary conditions. These children had a significantly reduced resistance, often extreme malnutrition and various kinds of chronic infectious diseases [23]. We deal here with a complex network of interrelationships between poor sanitation and socio-economic poverty, malnutrition, impaired immune function, infections and many diseases involving inflammatory agents $[24,25]$.

African children studies have shown that in groups suffering from protein-calorie deficiency, a significantly higher number of colonies of potentially pathogenic microorganisms is found in the oral environment, particu- 
larly of anaerobic microflora, when compared to properly nourished peers [26]. The most frequently isolated microorganisms in malnourished children are Prevotella melaninogenica, Porphyromonas gingivalis, Prevotella oralis, Prevotella ruminicola, Actinomyces israelii, Fusobacterium spp., Spirochaetes. Many of these microorganisms have the ability to stimulate host defense mechanisms and inflammatory response, which can initiate periodontal disease [27]. The reasons for the sudden increase in the number of colonies of potential periodontal pathogens in protein-calorie malnutrition are not clear. In health, the saliva always contains small basic peptides, particularly those with predominant histidine, lysine and arginine, as well as free amino acids and their metabolic products, such as polyamines, urea and ammonia. These substances are extremely important for the metabolism of many microorganisms that reside in the mouth. Arginine concentration in saliva is much higher, compared with other amino acids essential in the diet. Arginase activity (L-arginine aminohydrolase, EC 3.5.3.1) in the major salivary glands is one of the highest in extrahepatic tissues. It is believed that in the protein-calorie malnutrition there is a significant decrease in this enzyme activity in the salivary glands, which contributes to an increased availability of free arginine in the salivary secretions. Many of the oral bacteria, primarily anaerobic bacilli, utilize arginine in metabolic processes. These types of chemical reactions promote $\mathrm{pH}$ increase of the plaque, which in turn leads to the uncontrolled growth of periopathogenic microbial colonies and initiation of the process of periodontal tissue invasion by microorganisms and the development of inflammation [28].

Discussing the potential impact of malnutrition on the course of periodontal disease requires a reminder of the pathogenesis of this disease. The phagocytic cells, mainly neutrophils, are a measure of the cellular inflammatory response to bacterial antigens. In patients with congenital or acquired PMN dysfunction (neutrophil granulocytes, neutrophils, polymorphonuclear cells), periodontal tissues are damaged very rapidly, which suggests that neutrophils in periodontium play primarily a protective function. Intracellular disintegration of bacteria by neutrophils is mediated by reactive oxygen species (hydrogen peroxide - myeloperoxidase pathway), oxygen-dependent lipid peroxidation, and oxygen-independent mechanisms, involving toxic antibacterial granule release, comprising more than 20 different lysosomal enzymes. Of these, four proteolytic enzymes: serine proteinase elastase and two metalloproteinases (collagenase and gelatinase) possess the most damaging and destroying abilities for tissue structures, both for the cells and the extracellular matrix. Therefore, the release of reactive oxygen species and numerous neutrophil granules to extracellular environment can lead to local tissue destruction, which occurs in the course of periodontal diseases. Neutrophils are not passive cells that respond only to external signals. It has been shown that they play a very active role in the initiation and regulation of inflammation by secreting pro-inflammatory cytokines and the expression of MHC class II receptors, and thus they are involved in the activation and control of $\mathrm{T}$ cells. Inflammation is the price that the organism has to pay for the effective antimicrobial defense, wherein complex interaction takes place between cells and the potent soluble mediators, i.e. cytokines, various polypeptides generated by phagocytes, T cells and B cells, fibroblasts, keratinocytes and endothelial cells. Cytokines comprise all known interleukins, interferons (IFN- $\alpha$, IFN- $\beta$, IFN- $\gamma$ ), tumor necrosis factors (TNF- $\alpha$ and TNF- $\beta$ ), bacterial colony stimulating factors (G-CSF, M-CSF and GM-CSF), $\beta$ family of transforming growth factors (TGF- $\beta$ ), and other growth factors. During bacterial infection the following have fundamental importance: IL-1, IL- 6 and IL- 8 as well as TNF- $\alpha$, TNF- $\beta$ and IFN- $\gamma$, and additionally TNF receptors and antagonists of IL-1 receptor (IL-1Ra). However, IL-1 has the strategic importance for the result of infection control, especially in the case of infections caused by bacteria, because it is a potent inducer of the IL- 8 synthesis, which is an activator of neutrophils. It is believed that the increased concentration of IL- $1 \alpha$, IL- $1 \beta$ and TNF, and particularly IL-1 $\beta$, in the tissues with periodontal disease lesions, is an important factor stimulating alveolar bone resorption. In turn, IFN- $\gamma$, which inhibits in vitro the processes of bone resorption stimulated by IL- $1 \beta$, plays a critical role in the prevention of loss of the connective tissue attachment in periodontal disease. It should be emphasized that the action of cytokines in vivo is a very complex process, which cannot be easily predicted based solely on the knowledge of the activity of individual cytokines. Recent studies have indicated that tissue homeostatic mechanisms are regulated by cytokine cascades and networks, and are dependent on pre-existing potential of the target cell. For example, TGF- $\beta$ induces cartilage cells to produce collagen at an early stage of development, but this function is suppressed in the mature cells [29-33].

Dietary factors are important in the biology of cytokines. First of all, they modulate the synthesis and release of cytokines and their direct and indirect effects on target tissues, and also influence subsequent responses of these tissues. Protein-calorie malnutrition significantly reduces the ability to produce cytokines, hence the poor prognosis in the case of inflammatory changes in the affected people [34, 35].

Malnourished experimental animals demonstrated reduced levels of IFN- $\gamma$ in peripheral blood serum. A significant reduction in the production of interferons and a decrease in NK cell activity are recorded also in the case of vitamin A deficiency. Periodontal diseases have an episodic course with periods of healing and active tissue destruction. IFN- $\gamma$, TGF- $\beta$, IL- 4 and IL-1Ra are important in the recovery phase. A significant impairment in the synthesis of these cytokines is observed in malnutrition [36-38]. 
Despite the development of civilization and progress in dentistry, dental caries and periodontal diseases are still a serious social and medical problem. Research determining the relationship between the clinical state of oral health, selected immune parameters and indicators of nutritional status of the organism, is an alternative to other attempts undertaken to reduce these risks.

The authors declare no conflict of interest.

\section{References}

1. Grimble RF (1998): Modification of inflammatory aspects of immune function by nutrients. Nutr Res 18: 1297-1317.

2. Pomposelli JJ, Flores EA, Bistrian BR (1988): Role of biochemical mediators in clinical nutirion and surgical metabolism. JPEN J Parenter Eneral Nutr 12: 212-218.

3. Chandra RK (2002): Effect of Post-natal Protein Malnutrition and Intrauterine Growth Retardation on Immunity and Risk of Infection. In: Nutrition and Immune Function. Calder PC, Field CJ, Gill HS (eds.). CAB International Publishing, New York 2002; 41-56.

4. Grimble RF (1992): Dietary manipulation of the inflammatory response. Proc Nutr Soc 51: 285-294.

5. Chandra RK (1983): Numerical and functional deficiency in T helper cells in protein - energy malnutrition. Clin Exp Immunol 51: $126-132$

6. Boyd LD, Madden TE (2003): Nutrition, infection and periodontal disease. Dent Clin North Am 47: 337-354.

7. Pla GW (1994): Oral health and nutrition. Prim Care 21: 121133.

8. Willershausen B, Ross A, Försch M, et al. (2011): The influence of micronutrients on oral and general health. Eur J Med Res 16: 514-518.

9. Thurnheer T, Belibasakis GN, Bostanci N (2014): Colonisation of gingival epithelia by subgingival biofilms in vitro: role of "red complex" bacteria. Arch Oral Biol 59: 977-986.

10. Duran-Pinedo AE, Baker VD, Frias-Lopez J (2014): The periodontal pathogen Porphyromonas gingivalis induces expression of transposases and cell death of Streptococcus mitis in a biofilm model. Infect Immun 82: 3374-3382.

11. Bowden GH, Li YH (1997): Nutritional influences on biofilm development. Adv Dent Res 11: 81-99.

12. Zaura E, ten Cate JM (2004): Dental plaque as a biofilm: a pilot study of the effects of nutrients on plaque $\mathrm{pH}$ and dentin demineralization. Caries Res 38 (Suppl 1): 9-15.

13. Haraguchi A, Miura M, Fujise O, et al. (2014): Porphyromonas gingivalis gingipain is involved in the detachment and aggregation of Aggregatibacter actinomycetemcomitans biofilm. Mol Oral Microbiol 29: 131-143.

14. Könönen E, Müller HP (2014): Microbiology of aggressive periodontitis. Periodontol 2000 65: 46-78.

15. Figurski DH, Fine DH, Perez-Cheeks BA, et al. (2013): Target Mutagenesis in the Study of the Tight Adherence (tad) Locus of Aggregatibacter actinomycetemcomitans. Current Issues in Molecular Virology - Viral Genetics and Biotechnological Applications. Romanowski V (ed.). In Tech 2013; 43-70.

16. Srisatjaluk R, Kotwal GJ, Hunt LA, Justus DE (2002): Modulation of gamma interferon-induced major histocompatibility complex class II gene expression by Porphyromonas gingivalis membrane vesicles. Infect Immun 70: 1185-1192.
17. Cunningham-Rundles S (2002): Evaluation of the Effects of Nutrients on Immune Function. In: Nutrition and Immune Function. Calder PC, Field CJ, Gill HS (eds.). CAB International Publishing, New York 2002; 21-39.

18. Reddy V, Raghuramulu N, Bhaskaram C (1976): Secretory IgA in protein-calorie malnutrition. Arch Dis Child 51: 871-874.

19. Johnson DA, Sreebny LM, Enwonwu CO (1977): Effect on protein-energy malnutrition and of a powdered diet on the parotid gland and pancreas of young rats. J Nutr 107: 1235-1243.

20. Johansson I, Ericson T, Steen L (1984): Studies of the effect of diet on saliva secretion and caries development: the effect of fasting on saliva composition of female subjects. J Nutr 114: 2010-2020.

21. Taiwo JO (1993): Oral hygiene status and necrotizing ulcerative gingivitis in Nigerian children. J Periodontol 63: 1072-1074.

22. Alvarez JO (1995): Nutrition, tooth development and dental caries. Am J Clin Nutr 61: 410S-416S.

23. Alvarez JO, Lewis CA, Saman C, et al. (1988): Chronic malnutrition, dental caries and tooth exfoliation in Peruvian children aged 3-9 years. Am J Clin Nutr 48: 368-372.

24. Heinrich-Weltzien R, Zorn C, Monse B, Kromeyer-Hauschild K (2013): Relationship between malnutrition and the number of permanent teeth in Filipino 10- to 13-year-olds. Biomed Res Int 2013: 205950. doi: 10.1155/2013/205950. Epub.

25. Russell SL, Psoter WJ, Jean-Charles G, et al. (2010): Protein-energy malnutrition during early childhood and periodontal disease in the permanent dentition of Haitian adolescents aged 12-19 years: a retrospective study. Int J Paediatr Dent 20: 222-229.

26. Sawyer DR, Nwoku AL, Rotimi VO, Hagen JC (1986): Comparison of oral microflora between well-nourished Nigerian children. ASCD J Dent Child 53: 439-443.

27. Cook GC (1991): Tropical medicine. Postgrad Med J 67: 798822.

28. Enwonwu CO, Ilupeju F, Warren RC (1994): Arginine metabolism in the salivary glands of protein-deficient rats end its potential association with the oral microflora. Caries Res 28: 99-105.

29. Williams RC (1990): Periodontal disease. N Engl J Med 322: 373-382.

30. Genco RJ (1992): Host responses in periodontal diseases: current concepts. J Periodontol 63 (4 Suppl): 338-355.

31. Damgaard C, Holmstrup P, Van Dyke TE, Nielsen $\mathrm{CH}$ (2014): The complement system and its role in the pathogenesis of periodontitis: current concepts. J Periodontal Res. doi: 10.1111/12209. Epub.

32. Cheng WC, Hughes FJ, Taams LS (2014): The presence, function and regulation of IL-17 and Th17 cells in periodontitis. J Clin Periodontol 41: 541-549.

33. Khalaf H, Lönn J, Bengtsson T (2014): Cytokines and chemokines are differentially expressed in patients with periodontitis: possible role for TGF- $\beta 1$ as a marker for disease progression. Cytokine 67: 29-35.

34. Grimble RF (1989): Cytokines: their relevance to nutrition. Eur J Clin Nutr 43: 217-230.

35. Grimble RF (1998): Nutritional modulation of cytokine biology. Nutrition 14: 634-640.

36. Bhaskaram P, Sivakumar B (1986): Interleukin-1 in malnutrition. Arch Dis Child 61: 182-185.

37. Munoz C, Arevalo M, Lopez M, et al. (1994): Impaired interleukin -1 and tumor necrosis factor production in protein - caloric malnutrition. Nutr Res 14: 347-352.

38. Alves CC, Torrinhas RS, Giorgi R, et al. (2012): TGF- $\beta 1$ expression in wound healing is acutely affected by experimental malnutrition and early enteral feeding. Int Wound J 11: 533-539. doi: 10.1111/1742-481. 